\title{
Consensus on the Clinical Approach to Moderate-to-Severe Atopic Dermatitis in Spain: A Delphi Survey
}

\author{
Joaquín Sastre $\mathbb{D}^{1},{ }^{1}$ Esther Serra Baldrich, ${ }^{2}$ José Carlos Armario Hita, ${ }^{3}$ L. Herráez, ${ }^{4}$ \\ Ignacio Jáuregui, ${ }^{5}$ Ana Martín-Santiago, ${ }^{6}$ Javier Ortiz de Frutos, ${ }^{7}$ Juan Francisco Silvestre, ${ }^{8}$ \\ and Antonio Valero 9
}

${ }^{1}$ Service of Allergy, Fundación Jiménez Díaz, Madrid, CIBERES, Instituto Carlos III, Department of Medicine,
Universidad Autónoma de Madrid, Madrid, Spain
${ }^{2}$ Dermatology Unit, Hospital de la Santa Creu i Sant Pau, Barcelona, Spain
${ }^{3}$ Service of Dermatology, Hospital Universitario Puerto Real, University of Cádiz, Cádiz, Spain
${ }^{4}$ Service of Allergy, Hospital Universitario 12 de Octubre, Madrid, Spain
${ }^{5}$ Service of Allergy, Hospital Universitario Cruces, Barakaldo, Vizcaya, Spain
${ }^{6}$ Service of Dermatology, Hospital Universitari Son Espases, Palma, Spain
${ }^{7}$ Service of Dermatology, Hospital Universitario 12 de Octubre, Madrid, Spain
${ }^{8}$ Service of Dermatology, Hospital General Universitario de Alicante, Alicante, Spain
${ }^{9}$ Section of Allergy, Hospital Clinic i Provincial de Barcelona, IDIBAPS, Universitat de Barcelona, Barcelona, Spain

Correspondence should be addressed to Joaquín Sastre; jsastre@fjd.es

Received 3 December 2019; Accepted 18 February 2020; Published 7 April 2020

Academic Editor: Giuseppe Stinco

Copyright ( 2020 Joaquín Sastre et al. This is an open access article distributed under the Creative Commons Attribution License, which permits unrestricted use, distribution, and reproduction in any medium, provided the original work is properly cited.

\begin{abstract}
Background. The purpose of this study was to gather information on the current assessment and management of patients with moderate-to-severe AD in routine daily practice. Methods. A cross-sectional two-round Delphi survey with the participation of dermatologists and allergologists throughout Spain was conducted. They completed a 46-item questionnaire, and consensus was defined when responses of $\geq 80 \%$ of participants coincided in the categories of a 5-point Likert scale for that item. Results. A total of 105 specialists (aged 40-59 years) completed the two rounds. Participants agreed regarding the consideration of AD as a multifaceted disease and the differences in clinical presentation of $\mathrm{AD}$ according to the patient's age. It is recommendable to perform a skin biopsy to exclude early stage T-cell cutaneous lymphoma, psoriasis, or dermatitis herpetiformis, among others (99.1\%). Also, consensus was reached regarding the use of the SCORAD index to quantify the severity of the disease (86.7\%), the use of wet wraps to increase the effect of topical corticosteroids (90.4\%), the usefulness of proactive treatment during follow-up (85.6\%) and tacrolimus ointment (91.2\%) to reduce new flares, and the fact that crisaborole is not the treatment of choice for severe $\mathrm{AD}(92.4 \%)$. AD was not considered a contraindication for immunotherapy in patients with allergic respiratory diseases (92.4\%). In patients with severe $\mathrm{AD}$, the use of immune response modifier drugs (97.6\%) or phototherapy (92.8\%) does not sufficiently cover their treatment needs. Consensus was also obtained regarding the role of the new biologic drugs (93.6\%) targeting cytokines involved in the Th2 inflammatory pathway (92.0\%) and the potential role of dupilumab as first-line treatment (90.4\%) in moderate-to-severe AD patients. Conclusion. This study contributes a reference framework to the care of AD patients. There is no diagnostic test or biomarkers to direct treatment or to assess the severity of the disease, and many therapeutic challenges remain.
\end{abstract}

\section{Introduction}

Atopic dermatitis $(\mathrm{AD})$ is a chronic, pruritic, relapsing inflammatory skin condition, commonly affecting children and, to a lesser extent, adults. Infants with $\mathrm{AD}$ may develop a typical progression of atopic disorders, including allergic rhinitis, food allergy, and asthma at certain ages, a sequence commonly referred to as the atopic march [1, 2]. AD 
diagnoses are continuously on the rise, oscillating between $10 \%$ and $20 \%$ of the pediatric population. The disease affects $1-10 \%$ of adults worldwide, and recent studies have suggested that adult $\mathrm{AD}$ is more common than previously thought $[3,4]$. Although AD is not a life-threatening condition, it poses a significant social, psychological, and economic burden [5]. The negative psychosocial impact of $\mathrm{AD}$ on quality of life is well established $[5,6]$, with itching, scratching, sleep loss, and social embarrassment being among the most commonly reported difficulties contributing to school, work, and social struggles. Depression and anxiety have been reported to be also more common in adults with $\mathrm{AD}$, with these psychiatric symptoms being influenced by $\mathrm{AD}$ disease severity and the degree of impairment of quality of life [6].

The presentation of $\mathrm{AD}$ depends on age and ranges from papulovesicles to lichenified plaques. The pathogenesis of $\mathrm{AD}$ is multifactorial, including genetic, and environmental factors. Also, AD is characterized by skin barrier defects, immunologic dysfunction, and alterations in the skin microbiome [7-9]. However, a number of cytokines and mediators involved in Th2, Th22, Th17, and Th1 pathways appear to be important in $\mathrm{AD}$ pathogenesis, and there is currently an increasing interest in developing targeted therapies, especially for patients with moderate-to-severe forms of the disease not responding to conventional treatments [10-12]. Also, the disease is frequently associated with other comorbid skin conditions and extracutaneous diseases $[13,14]$. The causative mechanisms underlying these associations are poorly understood, but treating physicians should be aware of these associations while seeking to alleviate the burden for patients with $\mathrm{AD}$ [15].

Available evidence on different aspects of the disease is uncertain and scarce at the population level. There are two studies on the prevalence of severe AD in adults in Spain, one in three different areas (Asturias, Catalonia, and the Balearic Islands) in 2015-2016 and the other one in Madrid in 2016-2017; the estimated prevalence was $0.08 \%$ and $0.028 \%(0.015 \%$ for children), respectively $[16,17]$. AD was considered severe when the patient received a systemic immunosuppressant or a biologic (omalizumab, rituximab) during follow-up or had been hospitalized because of $\mathrm{AD}$ [16]. However, presently, there exists no gold standard for evaluating the severity of $\mathrm{AD}$ [18].

A study based on data from the 2016 National Health and Wellness Survey conducted in France, Germany, Italy, Spain, and the United Kingdom revealed that AD is associated with a significant disease burden and higher prevalence of atopic and psychological comorbidities, impaired health-related quality of life, lower work productivity, increased activity impairment, and increased healthcare utilization [19]. The Spanish Society of Allergology and Clinical Immunology carried out two wide-scale studies regarding the epidemiologic, clinical, and socioeconomic factors of the main allergic disorders in Spain, including $\mathrm{AD}[20,21]$.

However, no previous studies have evaluated the clinical approach to patients with $\mathrm{AD}$ at a national level in Spain. Therefore, a cross-sectional Delphi survey was designed to gather information on the assessment and management of patients with moderate-to-severe $\mathrm{AD}$ in conditions of routine clinical practice. The results of this study will be helpful to identify some of the unmet medical needs currently present in the care of these patients.

\section{Methods}

2.1. Study Design. A cross-sectional two-round Delphi survey was conducted over a 5-month period (between July 13 and December 5, 2017) with the participation of dermatologists and allergologists throughout Spain. The objective of the study was to develop a consensus document on the clinical approach to moderate-to-severe $\mathrm{AD}$ patients. The aims of the consensus were as follows: (a) to help clinicians in the assessment and management of $\mathrm{AD}$ patients in daily practice, (b) to know the current status of the care of patients with AD in Spain, and (c) to identify potential areas to improve outcomes, including early recognition of hallmark signs and symptoms to ensure correct diagnosis and use of evidence-based tools to determine disease impact and guide treatment decisions, and to promote patient engagement and adherence to therapies.

The Delphi method is generally accepted as a powerful means of reaching consensus and generating ideas among responders on a number of issues related to health problems in conditions of low grade evidence, knowledge, or application [22]. Briefly, the method involves sending a questionnaire to the responders and analyzing their response. This is then used to develop a new questionnaire and the cycle is repeated. Three methodological aspects are important in a Delphi study. First, responders or panelists are not aware of the identity of the other responders, to ensure that their responses are independent. Second, participants respond individually to avoid group domination by certain individuals. Third, mathematical voting procedures are used to permit the ranking of items. Likewise, there are no set guidelines for deciding on the optimum number of Delphi participants as this is likely to change depending on the purpose of the Delphi survey. The original Delphi method involves three or more rounds, whereas the modified technique is limited to two rounds to avoid losses of acceptable response rates due to prolonged duration of the process and the negative influence on the interest of the panelists. In the present study, a modified Delphi method was used to reach consensus.

2.2. Participants and Procedures. At the beginning of the project, a scientific committee formed by nine specialists, five dermatologists, and four allergologists with proven experience and interest in AD was established. Participants were authors of relevant research publications and were renowned professionals in the care of allergic patients, with expertise in AD. Two study coordinators (JS, ES) supervised the progression of the study, including recruitment of participants and results of analysis of data, as well as other organizational and logistic aspects of the project.

Items to be included in the study questionnaire were selected by members of the scientific committee based on a 
search of the literature to identify previously conducted studies with high level of evidence, such as systematic reviews and meta-analyses, and key primary studies focused on the field of moderate-to-severe $\mathrm{AD}$ in adult patients. Candidates to participate in the study were proposed by the study coordinators and members of the scientific committee. They were specialists in dermatology or allergology involved in the care of patients with $\mathrm{AD}$ in public hospitals and some private consultations throughout Spain, preferably with 5 or more years of experience and attending at least 10 patients with $\mathrm{AD}$ per month. The study questionnaire was lodged in an Internet microsite to which specialists who agreed to participate accessed via a weblink with the user's password.

The initial draft included 47 items, two of which were removed after the first round and a new item was added. Therefore, the final questionnaire was composed of a set of 46 items, in which questions were grouped into seven sections: definition and diagnosis (14 items), differential diagnosis (1 item), severity of AD (2 items), etiology and physiopathology (4 items), comorbidities of $\mathrm{AD}$ (4 items), health-related quality of life (2 items), and treatment and follow-up (19 items). Questions were formulated so that they could be answered using a 5-point Likert scale: 1: "strongly disagree," 2: "disagree," 3: "neither agree nor disagree," 4: "agree," and 5: "strongly agree." The study questionnaire is described in the Supplementary Materials.

2.3. Statistical Analysis. Only full completed questionnaires were considered. The consensus criteria included "unanimity" when $100 \%$ of the participants agreed on the same category of the Likert scale, "consensus" when agreement involved $\geq 80 \%$ of the participants, "majority" when agreement involved $\geq 70 \%$ of participants, and "discrepancy" when agreement involved $<70 \%$ of the participants. For the purpose of the analysis, "unanimity" and "consensus" groups were considered together as a consensus. Descriptive statistics included frequencies and percentages. The analysis was carried out trough consultation and analysis of the answers in the database from the online platform.

\section{Results}

3.1. Characteristics of Participants. Of a total of 200 dermatologists and allergologists who were invited to participate in the study, $125(62.5 \%)$ accepted and completed the first Delphi round, 105 (84\%) of which completed the second round. The final participation rate was $52.5 \%$. Of the 105 participants, 59 (56.2\%) were dermatologists and 46 (43.8\%) allergologists. The general profile of participants included a mean age between 40 and 59 years, 5 or more than 5 years of experience in the care of patients with $\mathrm{AD}$ with at least 10 patients with $\mathrm{AD}$ visiting per month (both children and adults), and $46.7 \%$ working in public hospitals, with all of them having available biologic drugs in the workplace.

3.2. General Results. After the two Delphi rounds, consensus was reached on 36 of the 46 items (78.3\%). There were 3 items where the agreement involved $\geq 70 \%$ of the participants (6.5\%) and there was discrepancy in 7 items (15.2\%). As shown in Table 1, the percentages of consensus ranged between $50 \%$ and $100 \%$, with the lowest percentages being in the sections of severity of $\mathrm{AD}$ and comorbidities and the highest percentages in the sections of differential diagnosis, etiology and physiopathology, and quality of life.

3.3. Definition and Diagnosis of $A D$. Of the 14 items included in this section, $12(85.7 \%)$ achieved consensus, and there was discrepancy in the remaining 2 (14.3\%) (Table 2). Participants agreed regarding the consideration of $\mathrm{AD}$ as a multifaceted disease derived from the interaction of multiple factors, including the skin components (96.8\%), the immune system (97.6\%), skin microbiome (89.6\%), and genetic (98.4\%) and environmental (98.4\%) factors. AD is diagnosed clinically (97.6\%) using the criteria of Hanifin and Rajka (94.3\%), with the clinical presentation depending on the patient's age (92.8\%), and currently lacking validated biomarkers that can help in the diagnosis of $\mathrm{AD}(83.2 \%)$. There were discrepancies in the usefulness of the classification of intrinsic and extrinsic $\mathrm{AD}$ as the basis of specific avoidance strategies $(60 \%)$ and eosinophil count as a biomarker of $\mathrm{AD}$ (37.1\%).

3.4. Differential Diagnosis. Participants agreed on the single item of this section, i.e., performing a skin biopsy to exclude other conditions, such as early stage T-cell cutaneous lymphoma, psoriasis, or dermatitis herpetiformis (99.1\%) (Table 3).

3.5. Severity of $A D$. Of the two items, consensus was reached on one regarding the use of the SCORAD (scoring atopic dermatitis) index to quantify the severity of the disease (86.7\%). There was discrepancy about eczema area and severity index (EASI) score as a validated scale that is not used in routine clinical practice $(58.1 \%)$ (Table 3$)$.

3.6. Etiology and Physiopathology. Of the four items, consensus was reached in all of them with the highest percentages regarding that "currently there is an unmet need in the treatment of moderate-severe AD" (98.4\%) and the statement that "a high percentage of patients with AD also present food allergy, allergic rhinitis, or asthma” (94.4\%) (Table 3).

3.7. Comorbidities. Of the four items, two achieved consensus regarding the fact that DA in children is frequently associated with allergic comorbidities (91.4\%) and that children with $\mathrm{AD}$ are more prone to suffer from mental disorders (84.8\%). There was no consensus about the association of $\mathrm{AD}$ in adults with allergic disorders $(78.1 \%)$ and a higher relative risk for immune-mediated inflammatory diseases (43.8\%) (Table 3).

3.8. Health-Related Quality of Life. Consensus was reached in the two items regarding $\mathrm{AD}$ as a cause of marked psychological anxiety (91.2\%) and the usefulness of patient- 
TABLE 1: General results obtained for the different sections of the questionnaire.

\begin{tabular}{lcccc}
\hline Section & Items $n$ & Consensus $n(\%)$ & Majority $n(\%)$ & Discrepancy $n(\%)$ \\
\hline 1. Definition and diagnosis & 14 & $12(85.7)$ & 0 & $2(14.3)$ \\
2. Differential diagnosis & 1 & $1(100)$ & 0 & 0 \\
3. Severity of AD & 2 & $1(50)$ & 0 & $1(50)$ \\
4. Etiology and physiopathology & 4 & $2(100)$ & $1(25)$ & 0 \\
5. Comorbidities of AD & 4 & $2(50)$ & 0 & $1(25)$ \\
6. Health-related quality of life & 2 & $14(73.7)$ & $2(10.5)$ & 0 \\
7. Treatment and follow-up & 19 & & $3(15.8)$ \\
\hline
\end{tabular}

AD: atopic dermatitis.

TABLE 2: Results regarding definition and diagnosis of AD.

\begin{tabular}{l}
\hline Item \\
$\begin{array}{c}\text { Consensus } \\
\text { (\%) }\end{array}$ \\
$\begin{array}{l}\text { Discrepancy } \\
\text { (i) AD can also develop de novo in adults or young adults, or even in advanced age }\end{array}$ \\
(ii) AD is a multifaceted disease that is derived from the interactions of multiple factors, including the \\
skin components (cellular and extracellular components that form the skin barrier) \\
(iii) AD is a multifaceted disease that is derived from the interactions of multiple factors, including the \\
immune system (innate and adaptative) \\
(iv) AD is a multifaceted disease that is derived from the interactions of multiple factors, including the \\
skin microbiome \\
(v) AD is a multifaceted disease that is derived from the interactions of multiple factors, including genetic \\
factors \\
(vi) AD is a multifaceted disease that is derived from the interactions of multiple factors, including \\
environmental factors \\
(vii) Currently, the diagnosis and assessment of the severity of AD are made on clinical grounds \\
(viii) The clinical criteria defined by Hanifin and Rajka are used for the clinical diagnosis of AD \\
(ix) The clinical presentation of AD depends on the age of the patients \\
(x) With greater frequency, children < 2 years of age and adults present involvement of the face and neck; \\
in addition, adults also present involvement of the flexor and extensor surfaces \\
(xi) Some forms of presentation seen in adults include dermatitis of the head and neck, chronic eczema of \\
the hands, and multiple zones of lichenification or prurigo \\
(xii) The classification of "intrinsic" AD (not associated with IgE) and "extrinsic" AD (associated with \\
IgE) has practical implications related to specific avoidance strategies in the management of the disease \\
(xiii) The blood eosinophil count is not a useful biomarker in AD \\
(xiv) Currently there are no validated biomarkers that help in the diagnosis of AD \\
\hline AD:
\end{tabular}

$\mathrm{AD}$ : atopic dermatitis; IgE: immunoglobulin E. ${ }^{*} 37.1 \%$ of disagreement.

oriented SCORAD (PO-SCORAD) for the self-assessment of $\mathrm{AD}$ in children, integrating the perspectives of the physician and the patient in the management of the disease $(91.2 \%)$ (Table 3).

3.9. Treatment and Follow-Up. Of the 19 items regarding different aspects of treatment and follow-up of patients with $\mathrm{AD}, 14(73.7 \%)$ obtained consensus, whereas most participants agreed on 2 items (10.5\%) and there were discrepancies in 3 (15.8) (Table 4). In the presence of positive prick tests, participants agreed on avoidance of suspected allergens $(83.8 \%)$ and dietary foods $(91.4 \%)$. There was consensus on the use of wet wraps to increase the effect of topical corticosteroids $(90.4 \%)$, the usefulness of proactive treatment during follow-up (85.6\%) and tacrolimus ointment (91.2\%) to reduce new flares, and the fact that crisaborole is not the treatment of choice for severe $\mathrm{AD}$ (92.4\%). Most of the participants $(72.4 \%)$ believed that the simultaneous combination on the same location of topical glucocorticoids and topical calcineurin inhibitors is not useful. Also, there was consensus that there are no enough bibliographic references supporting the use of antihistamines to alleviate pruritus $(85.7 \%)$ but there was discrepancy regarding the usefulness of antihistamines as systemic treatment of AD (64.8\%). Most participants agreed on the positive effects of allergen-specific immunotherapy (SIT) in some sensitized patients $(76.2 \%)$ and reached consensus that the item of $\mathrm{AD}$ is not a contraindication for immunotherapy in patients with allergic respiratory diseases $(92.4 \%)$. In patients with severe $\mathrm{AD}$, the use of immune response modifier drugs (97.6\%) or phototherapy (92.8\%) does not sufficiently cover their treatment needs. Participants agreed on the adequate risk-benefit ratio of cyclosporine (80.0\%) but disagreed on the adequate riskbenefit ratio of phototherapy $(69.5 \%)$. Finally, there was consensus on the role of the new biologic drugs (93.6\%) targeting cytokines involved in the Th2 inflammatory pathway $(92.0 \%)$ and the potential role of dupilumab as first-line treatment $(90.4 \%)$ in moderate-to-severe $\mathrm{AD}$ patients. By contrast, there was discrepancy regarding the position of Janus kinase (JAK) inhibitors in the treatment of $\mathrm{AD}(60.0 \%)$. 
TABLE 3: Results regarding differential diagnosis, severity of AD, etiology and physiopathology, comorbidities, and health-related quality of life.

\begin{tabular}{|c|c|c|c|}
\hline Item & $\begin{array}{c}\text { Consensus } \\
\text { (\%) }\end{array}$ & $\begin{array}{c}\text { Majority } \\
\text { (\%) }\end{array}$ & $\begin{array}{c}\text { Discrepancy } \\
(\%)\end{array}$ \\
\hline
\end{tabular}

Differential diagnosis

(i) In certain situations, skin biopsy should be considered to exclude other conditions, such as early stage T-cell cutaneous lymphoma, psoriasis, or dermatitis herpetiformis

Severity of AD

(i) The SCORAD index is used to quantify the severity of the disease in order to assess the comparative efficacy of treatments and progression of the disease in routine clinical practice (ii) The EASI score is a validated scale that is not used in routine clinical practice

86.7

Etiology and physiopathology

(i) A high percentage of patients with $\mathrm{AD}$ also present food allergy, allergic rhinitis, or asthma

(ii) Treatments oriented to increase filaggrin expression can be useful in the management of

$\mathrm{AD}$ in a particular group of patients

(iii)Currently there is an unmet need in the treatment of moderate-severe AD

(iv) Biologic drugs are especially promising for adult patients with moderate or severe forms of the disease

Comorbidities of $\mathrm{AD}$

(i) $\mathrm{AD}$ in adults is frequently associated with allergic comorbidities

(ii) $\mathrm{AD}$ in children is frequently associated with allergic comorbidities

(iii) The relative risk of suffering from immune-mediated inflammatory diseases such as rheumatoid arthritis and chronic inflammatory bowel disease is higher in patients with $\mathrm{AD}$ than in the general population

(iv) Children with $\mathrm{AD}$ are more prone to suffer from mental disorders such as depression, anxiety, and behavior disorders

Health-related quality of life

(i) $\mathrm{AD}$ causes considerable psychological anxiety and results in a dramatic impact on the quality of life for both patients and their families

(ii) The usefulness of PO-SCORAD for the self-assessment of AD in children suggests the importance of integrating the perspectives of the physician and the patient in the management of $\mathrm{AD}$

AD: atopic dermatitis; SCORAD: scoring atopic dermatitis; EASI: eczema area and severity index; PO-SCORAD: patient-oriented SCORAD. ${ }^{*} 43.8 \%$ neither agree nor disagree.

\section{Discussion}

The aim of the Delphi method is to obtain an opinion, level of agreement, or consensus on a current topic or concern from among a group of specialists or experts. This is an iterative and anonymous process with controlled feedback and analysis of the results widely used in health sciences. For this study, the percentage of unanimity, consensus, majority, and discrepancy has been decided taking into account the standard percentages that are usually used for a Delphi questionnaire of these characteristics and by agreement of the entire scientific committee. Although the Delphi methodology has been applied in various dermatological diseases [23-31], no previous studies comprising a consensus of opinion have been published on $\mathrm{AD}$ using the Delphi technique. In a multicenter international project, a Delphi study was conducted to reach consensus between different stakeholders on a core set of domains and items for registries of atopic eczema patients to collect data for research focused on photo- and systemic immunomodulatory therapies [32]. In this respect, given the paucity of Delphi studies on $\mathrm{AD}$, the present survey fills a gap in the literature.

With respect to the percentages of panelists having completed the rounds of questions set, the data varies depending on the characteristics of the study, including the number of experts, survey distribution methods, number of rounds, and face-to-face meetings. The overall participation rate in our study was $52.5 \%$, but the percentage of participants having completed the two Delphi rounds was $84 \%$, being in the upper band of the range over $60-80 \%$ reported in the literature $[33,34]$. In addition, the total number of 46 items was adequate, as high number of items is associated with significantly lower response rates [35].

In the opinion of the panelists, consensus was obtained regarding the consideration of $\mathrm{AD}$ as a multifaceted disease caused by the interaction of multiple factors. Recent studies of the etiopathogenesis of $\mathrm{AD}$ have highlighted the complex interplay among skin barrier deficiency, immunological derangement, which contributes to the development, progression, and chronicity of the disease [36]. Abnormalities in filaggrin, another stratum corneum constituent, and tight junctions induce and/or promote skin inflammation. This inflammation, in turn, can further deteriorate the barrier function by downregulating a myriad of essential barriermaintaining molecules [36]. The panel also agreed that the diagnosis of $\mathrm{AD}$ remains clinical without a reliable biomarker to confirm the diagnosis or assess the severity of the disease. Currently, biomarkers cannot be applied in daily 
TABLE 4: Results regarding treatment and follow-up of patients with AD.

\begin{tabular}{|c|c|c|c|}
\hline Item & $\begin{array}{c}\text { Consensus } \\
(\%)\end{array}$ & $\begin{array}{c}\text { Majority } \\
(\%)\end{array}$ & $\begin{array}{c}\text { Discrepancy } \\
(\%)\end{array}$ \\
\hline $\begin{array}{l}\text { Substances that should be avoided } \\
\text { (i) When the prick test is positive for any allergen with suspicion of clinical involvement, } \\
\text { avoidance of these allergens as far as possible may be a useful complementary measure } \\
\text { (ii) Patients with moderate-to-severe AD should follow a diet that does not include foods } \\
\text { testing positive in the prick test or prick-prick test and that are clinically relevant for the } \\
\text { patient }\end{array}$ & 83.8 & & \\
\hline $\begin{array}{l}\text { Topical and anti-inflammatory treatment } \\
\text { (i) The use of wet wraps increases the effect of topical corticosteroids } \\
\text { (ii) Proactive "treatment", for example, application for two times per week in long-term } \\
\text { follow-up, can help reduce new flares } \\
\text { (iii) Proactive "treatment" with application of tacrolimus ointment two times per week can } \\
\text { help reduce new flares } \\
\text { (iv) Simultaneous combination on the same location of topical glucocorticoids and topical } \\
\text { calcineurin inhibitors does not seem to be useful } \\
\text { (v) Based on results of clinical trials of crisaborole, this is not the treatment of choice for } \\
\text { severe AD }\end{array}$ & 92.4 & 72.4 & \\
\hline
\end{tabular}

Antipruritic treatment

(i) There are no sufficient bibliographic references supporting the general use of first- and second-generation antihistamines for treating pruritus in $\mathrm{AD}$

(ii) First- and second-generation antihistamines, in general, are not useful for systemic treatment of $\mathrm{AD}$

Allergen-specific immunotherapy (allergen-SIT)

(i) Allergen-SIT has positive effects in some sensitized patients with $\mathrm{AD}$

(ii) $\mathrm{AD}$ is not a contraindication for the use of immunotherapy in patients with allergic respiratory diseases (allergic rhinoconjunctivitis, allergic bronchial asthma)

Systemic treatments

(i) With the current immune response modifiers, the therapeutic needs of patients with severe $\mathrm{AD}$ are not sufficiently covered

(ii) In the treatment of severe $\mathrm{AD}$, cyclosporine has an adequate risk-benefit ratio

(iii)With phototherapy, the therapeutic needs of patients with severe AD are not sufficiently covered

(iv) In the treatment of severe $\mathrm{AD}$, phototherapy has an adequate risk-benefit ratio

New systemic treatments

(i) Treatment with biologic drugs should be considered in patients with severe AD not

controlled with conventional systemic and topical treatment

(ii) The objectives of these new biologic drugs should be targeting mainly cytokines involved in Th2 allergic inflammation such as IL-4, IL-5, IL-13, and IL-31

(iii) Dupilumab has the potential to become the new first-line reference treatment for patients with moderate-to-severe $\mathrm{AD}$ who are candidates for systemic treatment (with or without topical treatment)

(iv) According to results of phase II studies, JAK inhibitors will be a future treatment of AD

97.6

80.0

92.8

92.4

AD: atopic dermatitis; SIT: specific immunotherapy; IL: interleukin; JAK: Janus kinase. ${ }^{*} 60.0 \%$ neither agree nor disagree.

practice for diagnosing $\mathrm{AD}$, although they will play an increasingly important role in $\mathrm{AD}$ research and personalized medicine [37]. There were discrepancies regarding the usefulness of the classification of intrinsic and extrinsic AD as the basis of specific avoidance strategies, eosinophil count as a biomarker of $\mathrm{AD}$, and the use of EASI in clinical practice.

There was also consensus about differences in the clinical presentation of $\mathrm{AD}$ according to the patient's age. Even though many common features exist, there are significant differences between the clinical characteristics of children, adolescents, and adult AD subgroups [38]. Moreover, the lack of standardization of outcome measures for clinical signs of $\mathrm{AD}$, such as clinical signs measured with a physician-assessed instrument and symptoms measured with a patient-assessed instrument or control of flares, hampers comparison among studies [39]. Participants also agreed on the need to perform a skin biopsy to exclude other conditions, including early stage $\mathrm{T}$-cell cutaneous lymphoma, psoriasis, or dermatitis herpetiformis. In this respect, the clinical characteristics and the hallmark of Sézary syndrome, a leukemia variant of T-cell cutaneous lymphoma, often share striking similarities with AD [40].

In relation to comorbid conditions, allergic diseases in adults and depression, anxiety, and behavioral disorders in children were items for which consensus was obtained. A recent meta-analysis of 35 studies found that children and adolescents with $\mathrm{AD}$ had significantly higher risk of total 
mental disorders than those without $\mathrm{AD}$ (odds ratio [OR] 1.65; 95\% confidence interval [CI] 1.46-1.86), with an absolute risk of $12.6 \%$ [41]. Also, $\mathrm{AD}$ was recognized as the cause of considerable psychological anxiety. In fact, psychological stress is a significant contributor to $\mathrm{AD}$ disease course through its direct and indirect effects on immune response, cutaneous neuropeptide expression, and skin barrier function [42].

Consensus regarding treatment included the use of wet wraps to enhance the effect of topical corticosteroids, the use of proactive treatment in the affected area to reduce new flares, the recognition that crisaborole is not the treatment of choice for severe $\mathrm{AD}$, the adequate benefit-risk ratio of cyclosporine in severe $\mathrm{AD}$, the role of biologic drugs, targeting cytokines involved in allergic inflammation caused by Th2 helper lymphocytes, and the potential of dupilumab to become the new first-line treatment in patients with moderate-to-severe $\mathrm{AD}[43,44]$. A consensus was also reached on how to interpret skin prick test results. There was discrepancy in relation to the statement that first- and second-generation antihistamines are generally not useful in the systemic treatment of AD. Short-term, intermittent use of sedating antihistamines may be beneficial in the setting of sleep loss secondary to itch [45] but they reduce rapid eye movement (REM) sleep, produce daytime somnolence, impair learning, and reduce work efficiency [46]. It has been postulated that second-generation antihistamines may have anti-inflammatory effects. In human keratinocytes, histamine decreases the formulation of tight junctions and the expression of filaggrin, a gene responsible for $\mathrm{AD}$, via histamine $\mathrm{H} 1$ receptor (H1R) [47]. Furthermore, histamine regulates IL-31, a cytokine involving the skin barrier and pruritus, through H1R and induces the production of thymus and activation-regulated chemokine (TARC) via H4R [47]. Recently, in a randomized, double-blind, placebo-controlled, parallel-group study, a novel selective H4R antagonist, ZPL-3893787, showed significant reductions of EASI and SCORAD scores as compared with placebo, but a nonsignificant difference in the reduction of pruritus [48].

The results of the present study should be interpreted taking into account the fact that responses to the questionnaire reflect what the specialists would do in the different scenarios posed by each question, which may differ slightly from their clinical practice. However, the Delphi method allowed exploring systematically different clinical, diagnostic, and treatment aspects of patients with $\mathrm{AD}$, based on the qualified opinion of dermatology and allergology experts in the field. There is no diagnostic test or biomarkers to direct treatment or to assess the severity of the disease, and many therapeutic challenges remain. The extent to which activation of immune pathways in addition to Th2 signaling contributes to $\mathrm{AD}$ pathogenesis remains unknown [49], as well as whether new medications directed against targets believed to lead to AD will prove to be effective without significant risk.

In summary, this was a Delphi survey study of a sample of dermatology and allergology experts in the care of patients with $\mathrm{AD}$. The present consensus document contributes as a reference framework for the care of adult patients with moderate-to-severe $\mathrm{AD}$ in clinical practice.

\section{Data Availability}

The data used to support the findings of this study are included within the article.

\section{Conflicts of Interest}

Joaquín Sastre declares that he has received funding for his collaboration as a consultant for Thermo Fisher, Hycor Biomedical, Novartis, Sanofi Genzyme, LETIPharma, Mundipharma Pharmaceuticals, ALK, and GSK. On the other hand, he declares that he has received fees for conferences promoted by Novartis, GSK, Stallergenes, Sanofi Genzyme, Circassia, LETIPharma, and Faes Farma. $\mathrm{He}$ also states that he has received research grants from Thermo Fisher, Mundipharma Pharmaceuticals, ALK, and Sanofi Genzyme. Esther Serra declares that she has received fees for her collaboration as a consultant/speaker attending meetings and funding for her collaboration in different research projects promoted by Novartis, Sanofi Genzyme, GSK, LETIPharma, Faes Farma, MSD, Lilly, Amgen, AbbVie, and Pfizer. José Carlos Armario has received fees as a speaker and funding for meetings, congresses, and course attendance as well as for participating in a research project, promoted by AbbVie, Almirall, Galderma, ISDIN, Janssen, Leo-Pharma, Lilly, MSD, Novartis, Pfizer, and Sanofi Genzyme. Lys Herráez declares that she has received fees for her collaboration as a speaker and/or consultant for advisory boards, research projects, congresses, and course attendance for Novartis, Sanofi, GSK, AstraZeneca, ALKAbello, and Mundipharma. Ignacio Jáuregui declares that he has received funding from Sanofi Genzyme and Novartis for his collaboration in different meetings, as well as fees as speaker in online courses on atopic dermatitis and urticaria. He also declares that he has received funding from LETIPharma and Sanofi Genzyme for attending AAAAI Congress in 2019. On the other hand, he declares that he has received fees as a speaker from Sanofi and MSD. In respect of his participation in different research projects, he declares that he has received funding as a member of an advocacy group for Sanofi Genzyme (atopic dermatitis) and Novartis (chronic urticaria); furthermore he has worked as a consultant for Faes Farma and has been involved in several observational studies for Novartis. Ana Martín declares that she has received fees as a speaker in the conferences "Nonpharmacological Treatment for Atopic Dermatitis" and "Management of Patients with Atopic Dermatitis," both promoted by Sanofi Genzyme. She also declares that she has received funding for her collaboration as a consultant in research and for her assistance in the ESPD Congress, both promoted by Sanofi Genzyme. Javier Ortiz declares that he has received funding for his collaboration in different research projects promoted by Sanofi Genzyme, Novartis, Astellas Pharma, MSD, Uriach, and Laboratorios Viñas. Juan Francisco Silvestre has received fees as a speaker and funding for meetings, 
congresses, and course attendance as well as participating in a research project, all promoted by Sanofi Genzyme. Antonio Valero declares that he has received funding for meetings, congresses, and course attendance from LETIPharma, Novartis, Allergy-Therapeutics, and ALK and for his collaboration in different research projects promoted by Novartis, AstraZeneca, GSK, and Menarini. He also declares that he has participated in presentations promoted by Sanofi Genzyme, GSK, Novartis, Uriach, and Chiesi.

\section{Acknowledgments}

The authors would like to thank the experts who have participated as panelists: Águeda Pulpillo Ruiz, Alejandro Joral Badas, Alicia Enríquez Matas, Almudena Hernández Nuñez, Almudena Mateu, Amalia Pérez Gil, Amparo Pérez Ferriols, Ana Beristain Urquiza, Ana Batalla Cebey, Ana Bauza Alonso, Ana Isabel Tabar Purroy, Ana María Delgado Márquez, Ana Martín-Santiago, Ana Rosado Ingelmo, Angela Hernández Martín, Antonio Valero, Antonio Vélez García-Nieto, Araceli Sánchez, Arancha Jiménez, Ariel Callero Viera, Berta Pérez, Blanca Andrés López, Carmelo Escudero, Carmen D'Amelio Garófalo, César Rivas-Plata, Consuelo Fernández Rodríguez, Darío Antolín, David González De Olano, Diego De Argila, Eloína González Mancebo, Encarnación Antón Casas, Enrique Gómez De La Fuente, Enrique Jorquera, Esther Roé Crespo, Eulalia Baselga, Fernando Rodríguez Fernández, Francisco Javier Ruano Pérez, Francisco Javier Vicente Martín, Francisco José De León Marrero, Gloria Garnacho Saucedo, Gonzalo Bernaola Hortigüela, Hugo Vázquez Veiga, Idoia González Mahave, Ignacio Jáuregui Presa, Inmaculada Ruiz, Irán Sánchez Ramos, Isabel Betlloch, Isabel $\mathrm{M}^{\mathrm{a}}$ Sánchez Matas, J M Revelles, Javier Domínguez Ortega, Javier Mataix, Javier Miquel Miquel, Javier Ortiz de Frutos, Javier Pedraz, Javier Ruiz Hornillos, Jesús Tercedor Sánchez, Joaquín Sastre, José Carlos Armario Hita, José Luis García Abujeta, José Manuel Azaña Defez, José Manuel Barceló Muñoz, José Manuel Zubeldia Ortuño, José Suárez Hernández, Juan Francisco Silvestre, Juan Márquez Enríquez, Laura Berbegal, Lourdes Rodríguez Fernández-Freire, Lys Herráez Herrera, M. Bergón, María del Mar Moro, MM Sigüenza, Manuel Galán Gutiérrez, Mar Garcés Sotillos, Mar Reaño, Marcos Hervella, María Álvarez Puebla, María Antonia González Enseñat, María Ascensión Aranzábal Soto, Marta Feito Rodríguez, Marta Valdivielso Ramos, Mercedes Alcalde Alonso, Mercedes Rodríguez Serna, Milagros Lázaro Sastre, Miquel Casals Andreu, Mónica Venturini Díaz, Natalia Hernández Cano, Paloma Ibáñez Sandín, Paloma Poza Guedes, Pedro Manuel Gamboa Setien, Pedro Mercader García, Raúl De Lucas Laguna, Ricardo González, Ricardo Ruiz Villaverde, Ruth Barranco, Ruth Mielgo Ballesteros, Santiago Quirce Gancedo, Sara Isabel Palencia Pérez, Sergio Vañó, Sofía Ezsol, Susana Bel Pla, Susana Córdoba Guijarro, Susana Echechipía Madoz, Trinidad Repiso Montero, Violeta Zaragoza, and Yolanda Puente Crespo. The authors also thank GOC Networking for providing methodology advice during the study and Marta Pulido, MD, PhD, for the help in writing the manuscript and for the editorial assistance. This work was supported by a grant from Sanofi Genzyme SA.

\section{Supplementary Materials}

Study questionnaire. Section 1: definition and diagnosis. Section 2: differential diagnosis. Section 3: severity of AD. Section 4: etiology and physiopathology. Section 5: comorbidities of AD. Section 6: health-related quality of life. Section 7: treatment and follow-up. (Supplementary Materials)

\section{References}

[1] S. K. Bantz, Z. Zhu, and T. Zheng, "The atopic march: progression from atopic dermatitis to allergic rhinitis and asthma," Journal of Clinical \& Cellular Immunology, vol. 5, no. 2, p. 202, 2014.

[2] E. Serra-Baldrich, J. O. de Frutos, I. Jáuregui et al., "Changing perspectives in atopic dermatitis," Allergologia et Immunopathologia, vol. 46, no. 4, pp. 397-412, 2018.

[3] R. Sacotte and J. I. Silverberg, "Epidemiology of adult atopic dermatitis," Clinics in Dermatology, vol. 36, no. 5, pp. 595605, 2018.

[4] J. H. Son, B. Y. Chung, H. O. Kim, and C. W. Park, "Clinical features of atopic dermatitis in adults are different according to onset," Journal of Korean Medical Science, vol. 32, no. 8, pp. 1360-1366, 2017.

[5] A. T. M. Rønnstad, A.-S. Halling-Overgaard, C. R. Hamann, L. Skov, A. Egeberg, and J. P. Thyssen, "Association of atopic dermatitis with depression, anxiety, and suicidal ideation in children and adults: a systematic review and meta-analysis," Journal of the American Academy of Dermatology, vol. 79, no. 3, pp. 448-456.e30, 2018.

[6] M. J. Slattery, M. J. Essex, E. M. Paletz et al., "Depression, anxiety, and dermatologic quality of life in adolescents with atopic dermatitis," Journal of Allergy and Clinical Immunology, vol. 128, no. 3, pp. 668-671, 2011.

[7] J. Fenner and N. B. Silverberg, "Skin diseases associated with atopic dermatitis," Clinics in Dermatology, vol. 36, no. 5, pp. 631-640, 2018.

[8] S. F. Bremmer, J. M. Hanifin, and E. L. Simpson, "Clinical detection of ichthyosis vulgaris in an atopic dermatitis clinic: implications for allergic respiratory disease and prognosis," Journal of the American Academy of Dermatology, vol. 59, no. 1, pp. 72-78, 2008.

[9] M. G. Kirchhof, I. Landells, C. W. Lynde, M. J. Gooderham, and C.-h. Hong, "Approach to the assessment and management of adult patients with atopic dermatitis: a consensus document. Section I: pathophysiology of atopic dermatitis and implications for systemic therapy," Journal of Cutaneous Medicine and Surgery, vol. 22, no. 1_suppl, pp. 6S-9S, 2018.

[10] M. Megna, M. Napolitano, C. Patruno et al., "Systemic treatment of adult atopic dermatitis: a review," Dermatology and Therapy, vol. 7, no. 1, pp. 1-23, 2017.

[11] A. Dattola, L. Bennardo, M. Silvestri, and S. P. Nisticò, "What's new in the treatment of atopic dermatitis?" Dermatologic Therapy, vol. 32, no. 2, Article ID e12787, 2019.

[12] J. van der Schaft, J. L. Thijs, M. S. de Bruin-Weller, and D. M. W. Balak, "Dupilumab after the 2017 approval for the 
treatment of atopic dermatitis," Current Opinion in Allergy and Clinical Immunology, vol. 19, no. 4, pp. 341-349, 2019.

[13] G. C. Mohan and J. I. Silverberg, "Association of vitiligo and alopecia areata with atopic dermatitis," JAMA Dermatology, vol. 151 , no. 5 , pp. 522-528, 2015.

[14] E. Siegfried and A. Hebert, "Diagnosis of atopic dermatitis: mimics, overlaps, and complications," Journal of Clinical Medicine, vol. 4, no. 5, pp. 884-917, 2015.

[15] A. Paller, J. C. Jaworski, E. L. Simpson et al., "Major comorbidities of atopic dermatitis: beyond allergic disorders," American Journal of Clinical Dermatology, vol. 19, no. 6, pp. 821-838, 2018.

[16] A. Sicras-Mainar, R. Navarro-Artieda, L. Sánchez, and J. Sastre, "Prevalence of severe atopic dermatitis in adults in 3 areas of Spain," Journal of Investigational Allergology and Clinical Immunology, vol. 28, no. 3, pp. 195-197, 2018.

[17] B. Barroso, R. Vera-Berrios, J. Rial, M. Fariña-Sabaris, L. Santos, and J. Sastre, "Prevalence of severe atopic dermatitis in adults and children in a health area of Madrid, Spain," Journal of Investigational Allergology and Clinical Immunology, vol. 29, no. 1, pp. 77-79, 2019.

[18] R. Chopra and J. I. Silverberg, "Assessing the severity of atopic dermatitis in clinical trials and practice," Clinics in Dermatology, vol. 36, no. 5, pp. 606-615, 2018.

[19] L. Eckert, S. Gupta, A. Gadkari, P. Mahajan, and J. M. Gelfand, "Burden of illness in adults with atopic dermatitis: analysis of National Health and Wellness Survey data from France, Germany, Italy, Spain, and the United Kingdom," Journal of the American Academy of Dermatology, vol. 81, no. 1, pp. 187-195, 2019.

[20] Sociedad Española de Alergología e Inmunología Clínica, Alergológica 2005. Factores Epidemiológicos, Clínicos y Socioeconómicos de las Enfermedades Alérgicas en España en 2005, Sociedad Española de Alergología e Inmunología Clínica, Madrid, Spain, 2006.

[21] A. Martorell Aragonés, R. Félix Toledo, A. Martorell Calatayud, and J. C. Cerdá Mir, "Epidemiologic, clinical and socioeconomic factors of atopic dermatitis in Spain: alergológica-2005," Journal of Investigational Allergology and Clinical Immunology, vol. 19, no. Suppl 2, pp. 27-33, 2009.

[22] B. Graham, G. Regehr, and J. G. Wright, "Delphi as a method to establish consensus for diagnostic criteria," Journal of Clinical Epidemiology, vol. 56, no. 12, pp. 1150-1156, 2003.

[23] J. D. Cañete, E. Daudén, R. Queiro et al., "Elaboración mediante el método Delphi de recomendaciones para el manejo coordinado (reumatólogo/dermatólogo) de la artritis psoriásica," Actas Dermo-Sifiliográficas, vol. 105, no. 3, pp. 216-232, 2014.

[24] D. Engelman, L. C. Fuller, and A. C Steer, "Consensus criteria for the diagnosis of scabies: a Delphi study of international experts," PLoS Neglected Tropical Diseases, vol. 12, no. 5, Article ID e0006549, 2018.

[25] J. S. S. Concha, S. Pena, R. G. Gaffney et al., "Developing classification criteria for skin-predominant dermatomyositis: the Delphi process," British Journal of Dermatology, vol. 182, no. 2, pp. 410-417, 2019.

[26] E. Maverakis, C. Ma, K. Shinkai et al., "Diagnostic criteria of ulcerative pyoderma gangrenosum: a Delphi consensus of international experts," JAMA dermatology, vol. 154, no. 4, pp. 461-466, 2019.

[27] S. A. Elman, C. Joyce, F. Nyberg et al., "Development of classification criteria for discoid lupus erythematosus: results of a Delphi exercise," Journal of the American Academy of Dermatology, vol. 77, no. 2, pp. 261-267, 2017.
[28] A. Giménez-Arnau, M. Ferrer, J. Bartra et al., "Management of chronic spontaneous urticaria in routine clinical practice: a Delphi-method questionnaire among specialists to test agreement with current European guidelines statements," Allergologia et Immunopathologia, vol. 45, no. 2, pp. 134-144, 2017.

[29] V. Eleftheriadou, K. Thomas, N. van Geel et al., "Developing core outcome set for vitiligo clinical trials: international e-Delphi consensus," Pigment Cell \& Melanoma Research, vol. 28, no. 3, pp. 363-369, 2015.

[30] G. Girolomoni, G. Altomare, F. Ayala et al., "Differential management of mild-to-severe psoriasis with biologic drugs: an Italian Delphi consensus expert panel," Journal of Dermatological Treatment, vol. 26, no. 2, pp. 128-133, 2015.

[31] L. Puig, J. M. Carrascosa, I. Belinchón et al., "Adherencia y satisfacción del paciente y características organolépticas y de uso de los tratamientos tópicos utilizados para la psoriasis: consenso Delphi del panel de expertos y miembros del Grupo de Psoriasis de la Academia Española de Dermatología y Venereología," Actas Dermo-Sifiliográficas, vol. 104, no. 6, pp. 488-496, 2013.

[32] L. A. A. Gerbens, A. E. Boyce, D. Wall et al., "Treatment of Atopic eczema (TREAT) registry taskforce: protocol for an international Delphi exercise to identify a core set of domains and domain items for national atopic eczema registries," Trials, vol. 18, no. 1, p. 87, 2017.

[33] R. B. Akins, H. Tolson, and B. R. Cole, "Stability of response characteristics of a Delphi panel: application of bootstrap data expansion," BMC Medical Research Methodology, vol. 5, no. 1, p. 37, 2005.

[34] S. McPherson, C. Reese, and M. C. Wendler, "Methodology update," Nursing Research, vol. 67, no. 5, pp. 404-410, 2018.

[35] E. Gargon, R. Crew, G. Burnside, and P. R. Williamson, "Higher number of items associated with significantly lower response rates in COS Delphi surveys," Journal of Clinical Epidemiology, vol. 108, pp. 110-120, 2019.

[36] P. Rerknimitr, A. Otsuka, C. Nakashima, and K. Kabashima, "The etiopathogenesis of atopic dermatitis: barrier disruption, immunological derangement, and pruritus," Inflammation and Regeneration, vol. 37, no. 1, p. 14, 2017.

[37] J. Thijs, W. van Seggelen, C. Bruijnzeel-Koomen, M. de BruinWeller, and D. Hijnen, "New developments in biomarkers for atopic dermatitis," Journal of Clinical Medicine, vol. 4, no. 3, pp. 479-487, 2015.

[38] J. H. Son, B. Y. Chung, H. O. Kim, and C. W. Park, "Clinical features of atopic dermatitis in adults are different according to onset," Journal of Korean Medical Science, vol. 32, no. 8, pp. 1360-1366, 2017.

[39] J. Schmitt, S. Langan, S. Deckert et al., "Assessment of clinical signs of atopic dermatitis: a systematic review and recommendation," Journal of Allergy and Clinical Immunology, vol. 132, no. 6, pp. 1337-1347, 2013.

[40] I. Saulite, W. Hoetzenecker, S. Weidinger, A. Cozzio, E. Guenova, and U. Wehkamp, "Sézary syndrome and atopic dermatitis: comparison of immunological aspects and targets," BioMed Research International, vol. 2016, Article ID 9717530, 15 pages, 2016.

[41] Q.-W. Xie, X. Dai, X. Tang, C. H. Y. Chan, and C. L. W. Chan, "Risk of mental disorders in children and adolescents with atopic dermatitis: a systematic review and meta-analysis," Frontiers in Psychology, vol. 10, 2019.

[42] A. L. Suárez, J. D. Feramisco, J. Koo, and M. Steinhoff, "Psychoneuroimmunology of psychological stress and atopic 
dermatitis: pathophysiologic and therapeutic updates," Acta Dermato-Venereologica, vol. 92, no. 1, pp. 7-15, 2012.

[43] J. C. Armario-Hita, J. Pereyra-Rodriguez, J. F. Silvestre et al., "Treatment of moderate-to-severe atopic dermatitis with dupilumab in real clinical practice: a multicentre, retrospective case series," British Journal of Dermatology, vol. 181, no. 5, pp. 1072-1074, 2019.

[44] J. Sastre and I. Dávila, "Dupilumab: a new paradigm for the treatment of allergic diseases," Journal of Investigational Allergology and Clinical Immunology, vol. 28, no. 3, pp. 139-150, 2018.

[45] R. Sidbury, D. M. Davis, D. E. Cohen et al., "Guidelines of care for the management of atopic dermatitis," Journal of the American Academy of Dermatology, vol. 71, pp. 327-349, 2014.

[46] M. K. Church, M. Maurer, F. E. R. Simons et al., "Risk of firstgeneration H1-antihistamines: a GA2LEN position paper," Allergy, vol. 65, no. 4, pp. 459-466, 2010.

[47] Y. Ohsawa and N. Hirasawa, "The role of histamine H1 and $\mathrm{H} 4$ receptors in atopic dermatitis: from basic research to clinical study," Allergology International, vol. 63, no. 4, pp. 533-542, 2014.

[48] T. Werfel, G. Layton, M. Yeadon et al., "Efficacy and safety of the histamine H4 receptor antagonist ZPL-3893787 in patients with atopic dermatitis," Journal of Allergy and Clinical Immunology, vol. 143, no. 5, pp. 1830-1837, 2019.

[49] A. S. Paller, K. Kabashima, and T. Bieber, "Therapeutic pipeline for atopic dermatitis: end of the drought?" Journal of Allergy and Clinical Immunology, vol. 140, no. 3, pp. 633-643, 2017. 